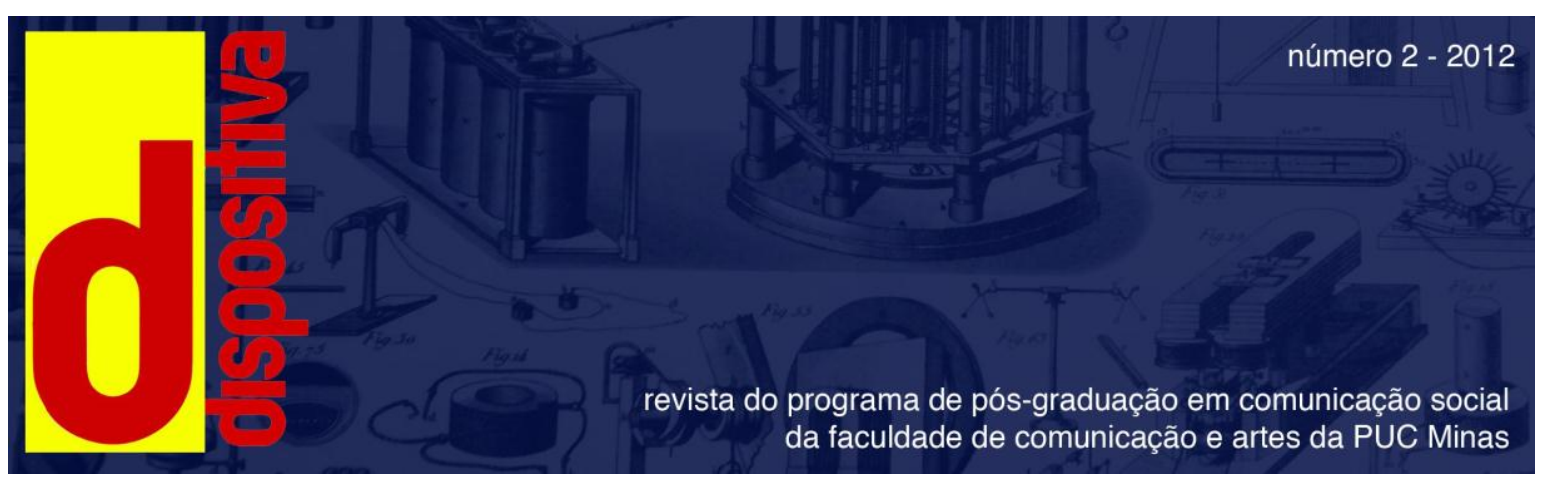

\title{
PALAVRA: ALEGRIA // WORD: HAPPINESS
}

\section{Bruno Vasconcelos de Almeida ${ }^{1}$}

\section{Resumo}

O objetivo do verbete é problematizar a ideia de alegria através de um dia e uma noite na vida de um adolescente imaginário. A alegria é algo experimental e se define pela singularidade, impessoalidade e incomunicabilidade. Os exemplos da literatura e da clínica favorecem um pensamento da alegria. No texto, trabalhamos com os conceitos de sentido, sensação e beatitude, alegria elevada à sua potência máxima. Do ponto de vista da experiência, a alegria é absolutamente dependente dos processos de produção e criação. Se não podemos reduzir a alegria a um objeto específico, visualizamos suas expressões nos campos estéticos, clínicos, éticos e políticos.

Palavras-chave: Alegria, beatitude, experiência.

\begin{abstract}
The objective of this paper is to debate the idea of joy taking a day and a night in the life of an imaginary adolescent as a basic reference. Joy is something experiential and characterizes itself as singular, impersonal and not communicable. The examples of literature and clinic can support a consideration of joy. In the text we work with the concepts of feeling, sensation and beatitude (beatitudo), which mean the highest level of joy. From the experience viewpoint, joy is absolutely dependent on the processes of production and creation. As it is impossible to reduce joy to a specific object, we will visualize its expressions in some fields such as aesthetics, clinical, ethical and political.
\end{abstract}

Key-words: Joy, beatitude, experience.

Somente o idiota pode definir a alegria. O adolescente esquizofrênico Míchkin de Cusa é um idiota, ele sustenta que a experiência da alegria está no encontro e na criação. É estranho que um louco pense na experiência, pois ele somente pode vivê-la,

\footnotetext{
${ }^{1}$ Psicólogo e Acompanhante Terapêutico. Professor Adjunto do Departamento de Psicologia da PUC Minas. Mestre e doutor em Psicologia Clínica pela PUC São Paulo.
} 
experimentá-la no corpo, fazê-la correr pelos dias de inverno e de verão. A intensidade e o vigor juvenis de Míchkin esgotam-se nos fluxos da seiva mineral que esvai ao fim do dia, e transformam-se em outra coisa, sem força e sem matéria.

Míchkin, o quase cartesiano, pensa na experiência a partir de seu estado emocional, de sua loucura, de seu sexo, de seu misticismo. Em seu êxtase confessional ele sabe que a experiência é impossível de ser transmitida, ela se dá por uma ausência ou por uma intersecção: entre teorias e práticas, entre discursos e instituições, entre o subjetivo e o objetivo, entre o normal e o patológico.

Um dia o adolescente teve um sonho, sonhou que era o rei do congado, a festa brasileira da mestiçagem negra onde os figurantes representam dramaticamente a coroação de um rei do Congo. Do sonho ele extraiu algumas ideias: a experiência é uma relação com o impensado, sempre nova e de difícil contextualização. Ela retorna sobre si e não no mais além, diríamos que a experiência é imanente a ela própria. O espaço de efetuação da experiência é a linguagem, seu exterior, seu fora conectivo. Ela se dá por uma espécie de exploração das margens, das divisas, das linhas percorridas sem que se dê conta dos pontos de partida. Mas acima de tudo, Míchkin extraiu a singularidade da experiência, sua natureza diferenciadora que torna impossível a apreensão.

Segue o resumo do sonho do adolescente: a experiência é singular, incomunicável, extrema e impossível. Em um comentário sobre a influência da obra de Georges Bataille no pensamento de Foucault, Macherey afirma que:

a experiência, fundamentalmente a do erotismo, quer dizer, do mal e da
morte, não pode ser separada do poder de contestação que exerce, não de
modo ininterrupto, mas de maneira necessariamente despedaçada, nestas
crises soberanas que dilaceram com seus terríveis abalos a linearidade
aparente da existência. (Macherey, 1999)

A experiência da alegria se desdobra no conjunto das experiências estéticas, éticas, clínicas e políticas. Múltipla e ao mesmo tempo singular, a alegria é uma experiência. Tomemos o exemplo da literatura: como experiência ela desemboca na função transgressora da linguagem, na possibilidade variável de invenção de línguas, narrativas e poéticas. De acordo com Blanchot (1987), a experiência da literatura abre o espaço literário, espaço para habitar que revela o inobjetivo, espaço inumano, espaço de distanciamento e dispersão.

De Blanchot a Foucault, encontramos a linha que vai do espaço literário, espaço de invenção singularizante, ao pensamento do fora, plano de composição de subjetividades não individuais, sem eu, e impessoais. No prefácio ao estudo de Foucault sobre 
Raymond Roussel, Pierre Macherey (1999) faz referência ao encontro de Foucault com os livros de Roussel, com estudos anteriores e as classificações da obra e do autor: para Pierre Janet, Roussel era doente; para André Breton, místico; para Michel Leiris, ingênuo. Foucault, ao contrário, impõe uma nova leitura, a do exercício absoluto do pensamento e da estilização da existência.

A experiência de Roussel, experiência com os jogos de linguagem e com os procedimentos, é uma experiência com os limites da linguagem, mas é, sobretudo, uma experiência com a vida, ou melhor, uma experiência de vida, uma conexão anotada por Deleuze (1997) em A Literatura e a Vida. Pierre Macherey (1999) faz análise parecida quando, ao localizar o sentido da fórmula foucaultiana 'loucura como ausência de obra', aponta para a relação contraditória com a linguagem: não é a loucura que produz obras, mas é antes a obra, à medida que corresponde a uma experiência de verdade, que se exclui em si mesma. Essa exclusão remete ao vazio e à facticidade.

Uma curiosa alegria se desprende quando percebemos a ressonância produzida na aproximação literatura e clínica. A clínica enquanto experiência produz saúde, mas ela igualmente coloca a relação contraditória com o sofrimento. Se a alegria guarda algum parentesco com o humor, é porque ambos colocam o problema do perspectivismo. $\mathrm{O}$ humor, que recoloca coisas e ideias em novas perspectivas, é uma das expressões da alegria.

Mas o adolescente acordou, precisa conhecer o mundo, ouve vozes, não as da loucura que o escravizam com ordens lancinantes, faça isto ou aquilo. Ouve vozes familiares, ou melhor, vozes de amigos. Como são poucos, pode diferenciar essas vozes, tonalidades e sons, pois também sabe na sua epistemologia precária que a voz é singular. O corpo fala não pelo sentido, mas pela sensação. $O$ despertar pela manhã se traduz em uma nova hospitalidade.

Michel Serres (2001) inverte a ordem: adormecer imita o sim, o despertar vira o não. Mergulhar, consentir, alçar-se à costa rochosa. Nascer a cada manhã ao nascimento do dia. Alegria. Esse atrelamento com os sentidos parece favorecer o pensamento de que não há nada no conhecimento que não passe pelas sensações. Mas isto não é verdadeiro, as matemáticas e as lógicas o desmentem. O adolescente encontra-se 
confuso, a comunicação e os dispositivos tecnológicos não ajudam, pois o tornam ainda mais insípido de si, perdido na variação infinita dos desdobramentos de si. Será preciso outro modo de colocar o problema da subjetividade e da alegria: produção e criação, hecceidades, fluxos e devires. Uma alegria dos processos e não uma alegria das formas, uma alegria na individuação e não uma alegria do indivíduo.

De acordo com Serres (2001), são três as alegrias do corpo: saltar, andar e correr. Contudo, o corpo porta o peso, porta uma ideia de carga ou a carga, e porta a leveza. O exemplo do bailarino que alça o corpo da bailarina, o peso leve, peso pluma, peso que tem um peso e não pesa. A dança reina antes da linguagem, como música do corpo (Serres, 2001).

Ao escutar as vozes, acolhido pela hospitalidade do dia, Míchkin imagina que a leveza e o peso encontraram outro arranjo que não o dialético. Uma alegria bem humorada que o redime de outros pesadelos, que o desliga do insuportável para uma corrida matinal que vivifica seu corpo.

Como gostaria de dizer, invertendo a perspectiva como um dedo de luva, que a literatura, a filosofia e o pensamento começam quando o pedante sai. Quando o saber pesado se retira. Quando a língua-chavão queima. Quando a prisão da linguagem se abre. Enfim livres, livres para falar a nosso belprazer, sem regras azedas nem referências canônicas, para pensar à nossa vontade, leve, sem dogma prévio, nem crítica interminável, para escrever galantemente longe dessa presença pesada. Para escrever a uma mulher, mas nunca contra um revisor. (Serres, 2001, p.342)

Após sua corrida e seu desjejum, o adolescente com nome de príncipe, mas preso pelas origens à filiação divina, é lançado novamente ao mundo das palavras e do pensamento. A experiência da alegria está no encontro, um modo de ser afetado e afetar, e ao mesmo tempo uma espécie de afectologia se desenha como ciência dos afectos. Dessas alegrias que afetam, podemos experimentar suas formações mutantes na clínica, como espaço privilegiado desta afetação; na arte, como possível para a produção de afectos e perceptos; ou na política, como espaço de criação do comum e do múltiplo.

O dia passa, Míchkin se põe a escrever. O príncipe conhece a literatura e a ciência, gosta especialmente da primeira e desenha letras no espaço projetado pelo jogo de luz e sombras de seu quarto. A literatura tem diferentes desdobramentos no pensamento francês: em Foucault, ela é o laboratório onde se elabora o estatuto de uma experiência; em Bataille, a literatura é uma experiência de produção de subjetividade entre dois 
pólos, o do erotismo e o da violência; já para Canguilhem é a ciência que tem a primazia sobre a literatura, trata-se da experiência de flutuações vitais e da relatividade das categorias do normal e do patológico. Míchkin afirma que escrever é pensar e, portanto, a literatura é filosofia.

A literatura se processa em margens psíquicas e muitas vezes é uma terapêutica. Nela encontramos uma sintomatologia crítica da clínica. Deleuze distingue em medicina três atos diferentes: a sintomatologia ou procura dos signos, a etiologia ou procura das causas, e a terapêutica ou procura dos tratamentos. De modo similar, definimos como clínica os procedimentos de observação e descrição (semiologia), classificação e distinção (diagnóstico), relação entre causas e efeitos (etiologia) e, por último, tratamento e cura (terapêutica). A experiência da alegria aí não se encontra, mas igualmente ela não se encontra no mais-além; a experiência da alegria é absolutamente dependente de produção e criação, e nisto ela guarda pontos de contato e ressonância com a literatura.

Os efeitos da alegria são reais, eles fazem explodir as situações de clausura em que o nó subjetivo encontra-se enredado. É alegria ou - era, outra vez em quando, a Alegria (Rosa, 1985), a experiência do bebê no olhar da mãe, a morte suspensa no pelotão de fuzilamento, a relação do misticismo com a poesia, ou então, a composição do sol com a pele, o som das ondas do mar, o verso de E. E. Cummings ou a prosa de Hermann Broch.

Bêbado de tanta alegria colhida na criação, o adolescente entra na noite experimentando o poder de hesitação objetiva dos corpos, essa zona de variação que Deleuze (1996) chamou de Corpo sem Órgãos, que em um processo díspar e ressoante captura e libera suas forças de composição, fazendo explodir sua quietude, sua zona de conforto, sua morte em vida. Ao adormecer, Míchkin encontra a tela branca, ou então experimenta novo estranhamento, desta vez ainda mais forte, o corpo esquizo parece se desmembrar na intensidade das forças que o atravessam e aí, no instante condensador e dissipador, instante eterno, o louco, que não é mais adolescente nem velho, experimenta uma beatitude.

A alegria elevada a sua potência máxima chama-se beatitude. Eis porque Míchkin sustenta que a experiência da alegria está no encontro e na criação. Mas ele descobre 
sonhando dois novos conceitos que dizem respeito à alegria e a beatitude: campo transcendental e vida. Noite adentro, em sono profundo e sonho desmedido, sonho como virtualidade, Míchkin gostaria de experimentar a vida em sua intensidade máxima; contudo, ele suspeita que tal experimentação coincida com seu fim, com sua imersão no caos e com micro explosões no delicado abismo da loucura. O campo transcendental corresponde aos dados imediatos, distintos da experiência na medida em que não remetem nem a um sujeito nem a um objeto. Deleuze (s/d) afirma que o campo transcendental se define por um plano de imanência, e o plano de imanência se define por uma vida. Uma vida está por todos os lugares, feita de virtualidades e acontecimentos. A vida, simplesmente a vida. A noção de alegria está atrelada ao conceito de vida.

Em sonho, Míchkin de Cusa adentra a biblioteca do palácio onde mora em busca dos materiais da alegria: os fluxos de consciência de William James, o self-enjoyment de Whitehead, a alegria ética de Espinosa, os caminhos de Zaratustra. Pensar e sonhar em um mesmo plano de imanência, o limite tenso de uma vida em diferenciação complexa e intensiva.

Gilles Deleuze (Abecedário) cita dois curiosos exemplos de alegria: a queixa e o lamento. O queixoso e o lamuriento dizem algo que não podem suportar, algo grande demais para eles, seja o hipocondríaco, seja a elegia. Figuras de uma exclusão sem estatuto definido, o queixoso e o lamuriento são expressões de uma experiência no limite, experiência do insuportável, maior do que o sujeito ou o objeto.

Do sono absoluto e eterno, no mais profundo da noite, Míchkin não se lembrará. Agora é noite, e depois outro dia, e depois outro, e a alegria se desenha como de fato aquilo que ela é: miragem, experiência dos sentidos, simplesmente alegria. 


\section{Referências}

Deleuze, Gilles. Crítica e Clínica. Tradução Peter Pál Pelbart. São Paulo: Editora 34, 1997. (Coleção TRANS).

Deleuze, Gilles. A Imanência: uma vida. (s/d). Disponível em: http://www.letras.ufrj.br/ciencialit/terceiramargemonline/numero11/xiii.html. Acesso em 30/05/2012.

- Deleuze, Gilles e Guattari, Félix. O Que é a Filosofia? Tradução Bento Prado Jr. E Alberto Alonso Muñoz. Rio de Janeiro: Editora 34, 1992.

Deleuze, Gilles e Guattari, Félix. Mil Platôs: Capitalismo e Esquizofrenia. Volume 3. Tradução Aurélio Guerra Neto, Ana Lúcia de Oliveira, Lúcia Cláudia Leão e Suely Rolnik. Rio de Janeiro: Editora 34, 1996. (Coleção TRANS).

Deleuze, Gilles e Parnet, Claire. Abecedário. Disponível em: < http://www.ufrgs.br/corpoarteclinica/obra/abc.prn.pdf. > Acesso em: 10/05/2012.

Blanchot, Maurice. O Espaço Literário. Tradução Álvaro Cabral. Rio de Janeiro: Editora Rocco, 1987.

Foucault, Michel. Raymond Roussel. Tradução Manoel Barros da Motta e Vera Lúcia Avellar Ribeiro. Rio de Janeiro: Forense Universitária, 1999.

Rosa, João Guimarães. Primeiras Estórias. 14ª Edição. Rio de Janeiro: Nova Fronteira, 1985. 
Roussel, Raymond. Impresiones de Africa. Traducción Maria Teresa Gallego y Maria Isabel Reverte. Madrid: Ediciones Siruela, 1990.

Serres, Michel. Os cinco sentidos. Tradução Eloá Jacobina. Rio de Janeiro: Bertrand Brasil, 2001. (Filosofia dos Corpos Misturados; 1).

Sokolov, Sasha. Escola para bobos. Tradução Konstantin Asryantz e Svetlana Kardash. São Paulo: Ars Poetica, 1993. 